\title{
Editorial: Sustainability Challenges for Our Urban Futures
}

\author{
Ana E. Escalante ${ }^{1 *}$, Hallie Eakin ${ }^{2}$ and Constantino Macias García ${ }^{3}$ \\ ${ }^{1}$ Laboratorio Nacional de Ciencias de la Sostenibilidad, Instituto de Ecología, Universidad Nacional Autónoma de México, \\ Mexico, Mexico, ${ }^{2}$ School of Sustainability, Arizona State University, Tempe, AZ, United States, ${ }^{3}$ Departamento de Ecología \\ Evolutiva, Instituto de Ecología, Universidad Nacional Autónoma de México, Mexico, Mexico
}

Keywords: urban sustainability, socio - ecological system, collaborative decision-making, transformative change, urban governance and planning

\section{Editorial on the Research Topic}

\section{Sustainability Challenges for Our Urban Futures}

Today, more than $50 \%$ of the human population lives in cities. This percentage is expected to rise to $70 \%$ by the year 2050 (United Nations, 2016), and will probably keep increasing for the foreseeable future. By enabling accumulation of resources and knowledge, urbanization has had a great impact on improving quality of life, but it also poses difficult challenges for planning and management of the built and natural environment, the provision of urban services, and the design of equitable economic policy (Dye, 2008; UN-HABITAT, 2017). The complex historical, socioeconomic, political, and biophysical drivers of urban growth result in significant spatial heterogeneity in terms of social and demographic characteristics, natural resources, and social, economic and physical infrastructure. This heterogeneity reinforces inequalities in the provision of urban services and exposure to hazards. Such inequalities are exacerbated by biases in the responses

\section{OPEN ACCESS}

Edited and reviewed by:

André Mascarenhas,

Humboldt University of Berlin, Germany

*Correspondence: Ana E. Escalante anaelena.escalante@gmail.com

Specialty section: This article was submitted to Land Use Dynamics,

a section of the journal

Frontiers in Environmental Science

Received: 15 September 2020 Accepted: 04 November 2020 Published: 26 November 2020

Citation:

Escalante $A E$, Eakin $\mathrm{H}$ and Macias García C (2020) Editorial: Sustainability Challenges for Our Urban Futures.

Front. Environ. Sci. 8:606777. doi: 10.3389/fenvs.2020.606777 and interventions of city managers and infrastructure providers (McGranahan et al., 2001; Ahern, 2013; Eakin et al., 2017; Pickett et al., 2017; Zhou et al., 2017). In cities, social and political processes are created and reinforced through actions of residents, governments, and decision-makers, who in turn influence the creation of the built environment, its socio-economic heterogeneity and the concomitant, uneven vulnerability to hazards (Eakin et al., 2017).

In this Research Topic we present papers that provide novel ideas and empirical results on how decision-makers can better govern urbanization and urban well-being in the context of globalization, climate change, and inequalities. In particular, articles in this collection include methodological and empirical contributions that illustrate the importance of social-ecological and technical coupling in the urban context. Collectively, these contributions support an expansion of the domains in which urban decisions and planning strategies must take place to promote more sustainable, and more equitable expressions of urban life. All articles in this Topic highlight the unequal participation of different actors and stakeholders in the process of making decisions in the face of an array of urban sustainability problems, and stress the major importance of inclusion of all relevant actors and stakeholders when planning for sustainable cities.

In the context of climate change, hydrometeorological events that hit cities have increased both in frequency and in intensity, and the impact of these events and urban strategies for recovery are a focus of investigation for better planning and management. In this respect, the contribution of Beckingham et al. provides a critical overview of the evolution of stormwater management approaches in urban centers in Southeastern USA, arguing in favor of better socio-ecological design that incorporates transdisciplinary work. The authors make the case for the critical importance of engaging different actors and stakeholders to conceive and implement sustainable solutions, including not only the biophysical and technical aspects of building infrastructure, but also the 
appropriate management and social appreciation of the provision of ecological services. In their article, Aguilar-Barajas and Ramirez describe the impact of, and recovery from, a major hurricane hitting northern Mexico. Their contribution focuses on the transdisciplinary work of the "State Reconstruction Council," a government taskforce especially designed to deal with the crisis. In a matter of weeks the Council reinstated infrastructure and services that were severely damaged or destroyed. The authors advocate for the creation of this type of institution as a permanent vehicle for sustainable urban planning and management.

Beyond creating institutions charged with promoting transdisciplinary work for urban management, sustainable cities require the generation and availability of relevant and credible information for stakeholders. Three contributions of the Topic deal directly with the production and analysis of information relevant for decision making in urban planning settings. The article by Mazari-Hiriart et al. characterizes the quality of water in supply wells in Mexico City, while considering the potential for contamination due to their closeness to geological fractures. This work reflects on and makes visible water vulnerabilities that go beyond the availability and exploitation of water sources, serving as a reminder of the importance of locally salient analyses of urban vulnerabilities. Another contribution dealing with the challenges of information for planning is presented by Estrada et al.. In their work, the authors advocate analytical approaches that can unveil critical aspects of urban sustainability in the context of climate change. Their methodological proposal addresses the complexity of information characterizing urban realities and climate uncertainties, with the ultimate aim of guiding policy. At finer scale, Zambrano, Aronson et al. present a case study of the consequences for and evaluation of sustainability of land fragmentation in Mexico City, going beyond the biophysical dimension of sustainability to include metrics of human well-being and social benefits of green areas.

A substantial proportion of the contributions to the Topic focuses on the importance of coproduction of knowledge for

\section{REFERENCES}

Ahern, J. (2013). Urban landscape sustainability and resilience: the promise and challenges of integrating ecology with urban planning and design. Landsc. Ecol. 28, 1203-1212. doi: 10.1007/s10980-012-9799-z

Dye, C. (2008). Health and urban living. Science 319, 766-769. doi: 10.1126/science. 1150198

Eakin, H., Bojórquez-Tapia, L. A., Janssen, M. A., Georgescu, M., ManuelNavarrete, D., Vivoni, E. R., et al. (2017). Opinion: urban resilience efforts must consider social and political forces. Proc. Natl. Acad. Sci. U.S.A. 114, 186-189. doi: 10.1073/pnas.1620081114

McGranahan, G., Jacobi, P., Songsore, J., Surjadi, C., and Kjellén, M. (2001). The Citizens at Risk: From Urban Sanitation to Sustainable Cities Earthscan. London: Routledge.

Pickett, S.T.A., Cadenasso, M. L., Rosi-Marshall, E. J., Belt, K. T., Groffman, P. M., Grove, J. M., et al. (2017). Dynamic heterogeneity: a framework to promote ecological integration and hypothesis generation in urban systems. Urban Ecosyst. 20, 1-14. doi: 10.1007/s11252-016-0574-9

UN-HABITAT (2017). New Urban Genda. urban sustainability transformations. These papers address the ubiquitous hegemony of exogenous narratives as a frequent hindrance, and propose the inclusion of a diversity of actors and local narratives for the analysis of the challenges and opportunities of sustainable urban planning and management. Four examples of efforts for transformative, transdisciplinary work in urban planning for sustainable futures are presented in this group of articles: (i) Zambrano, Cano-Santana et al., focus on the management of urban green spaces and the need to identify conflicts and synergies among stakeholder viewpoints, (ii) Priya et al., present a data-informed reflection on the effectiveness of a formal imported model of planning for health provision in India vs. informal solutions, (iii) Eakin et al. explore and document the need to make visible the metanarratives and associated solutions for urban problems such as water vulnerabilities as means of identifying possibilities for more sustainable management, and (iv) Randhawa et al. present a case study focused on waste management that provides important lessons for the role of transdisciplinary research in urban sustainability transformations.

The multifarious nature of urban realities, urban challenges and urban traditions is evident in this small sample of reports. Dealing mostly with regions in tropical North America, and exclusively on middle/low income cities around the tropic of Cancer, they nevertheless display the bewildering diversity of empirical and conceptual approaches to urban sustainability. One commonality emerges, though, and is that whatever the particular challenges facing cities, it is only through the concert of all stakeholders and decision-makers that urban humans will be able to move toward sustainable goals and supporting transformative change.

\section{AUTHOR CONTRIBUTIONS}

$\mathrm{AE}, \mathrm{HE}$, and $\mathrm{CM}$ proposed the Research Topic, edited manuscripts, and wrote the editorial. All authors contributed to the article and approved the submitted version.
United Nations (2016). The World's Cities in 2016: Data Booklet. Economic and social affair, 29. Available online at: http://www.un.org/en/development/desa/ population/publications/pdf/urbanization/the_worlds_cities_in_2016_data_ booklet.pdf.

Zhou, W., Pickett, S.T.A., and Cadenasso, M.L. (2017). Shifting concepts of urban spatial heterogeneity and their implications for sustainability. Landsc. Ecol. 32, 15-30. doi: 10.1007/s10980-016-0432-4

Conflict of Interest: The authors declare that the research was conducted in the absence of any commercial or financial relationships that could be construed as a potential conflict of interest.

Copyright (C) 2020 Escalante, Eakin and Macias García. This is an open-access article distributed under the terms of the Creative Commons Attribution License (CC BY). The use, distribution or reproduction in other forums is permitted, provided the original author(s) and the copyright owner(s) are credited and that the original publication in this journal is cited, in accordance with accepted academic practice. No use, distribution or reproduction is permitted which does not comply with these terms. 